Available online on 15.02.2020 at http://jddtonline.info
Open Access to Pharmacentical and Medical Research
unrestricted non-commercial use, provided the original work is properly cited

Open Access

Short Communication

\title{
Antidyslipidaemic and cardioprotective effects of turmeric (Curcuma longa) in rat fed a high cholesterol diet
}

\author{
*Uchendu Ikenna Kingsley, Ekeigwe Ifeoma Blessing, Nnedu Ebuka Bitrus \\ Department of Medical Laboratory Science, University of Nigeria, Enugu, Nigeria
}

\begin{abstract}
Objective: The aim of this study is to evaluate the antidyslipidaemic and cardioprotective effects of aqueous extract of Curcuma longa (AECL) in rats fed a high cholesterol diet (HCD).

Methods: Twenty (20) rats were randomly grouped into four groups: A-D of five animals per group. Groups A-C received HCD (2000mg/kg, oral) and carbimazole $(60 \mathrm{mg} / \mathrm{kg}$, oral) daily for eight weeks. Group A served as negative control. Group B (positive control) was treated with atorvastatin $(20 \mathrm{mg} / \mathrm{kg})$, while group C served as treatment group and received AECL (400mg/kg) daily for eight weeks. Group D s erved as normal control and received no treatment. After the administration, biochemical markers of Lipid profiles (total cholesterol (TC), triglycerides (TG) and high density lipoprotein cholesterol (HDL-C)) were assayed using standard methods. The hearts of the rats were harvested for histopathological studies.
\end{abstract}

Results: AECL significantly induced hypolipidaemia and stabilized lipid biochemical markers $(\mathrm{p}<0.05$ or $\mathrm{p}<0.01)$; and protected the cardiac muscle fibres from injuries.

Conclusion: Tumeric (Curcuma longa) has antidyslipidaemic and cardioprotective effects.

Keywords: antidyslipidaemia, cardioprotection, Curcuma longa, ethnopharmacology, hypercholesterolaemia, Medicinal foods, cardiomyopathy

Article Info: Received 28 Nov 2019; $\quad$ Review Completed 16 Jan 2020; $\quad$ Accepted 29 Jan 2020; Available online 15 Feb 2020

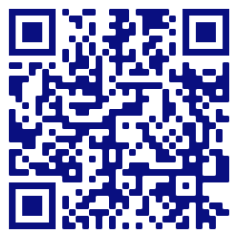

Cite this article as:

Uchendu IK, Ekeigwe IB, Nnedu EB, Antidyslipidaemic and cardioprotective effects of turmeric (Curcuma longa) in rat fed a high cholesterol diet, Journal of Drug Delivery and Therapeutics. 2020; 10(1-s):178-181 http://dx.doi.org/10.22270/jddt.v10i1-s.3869

Uchendu Ikenna Kingsley, Department of Medical Laboratory Science, University of Nigeria, Enugu State, Nigeria

\section{INTRODUCTION}

A few foods of plant origin and plants species have been thoroughly evaluated for their therapeutic and/or toxicological profile. Foods or plants with medicinal value have proven to be most useful in the treatment of diseases in most of the developing countries, and they provide important sources of most of the world's pharmaceutical.

It has been reported that rats with hypercholesterolaemia risk the development of systemic organ complications, including heart injury. ${ }^{1}$ Thus investigation into the prevention and treatment of abnormal cholesterol levels or heart injury complications, with a simple and common nutritional plant like Curcuma longa, is an important step in maintaining optimum health. The aim of this research was to evaluate the antidyslipidaemic and cardioprotective effects of aqueous extract of curcuma longa in hypercholesterolaemic albino rats.

\section{MATERIALS AND METHODS}

\section{Tumeric}

Fresh samples of tumeric (Curcuma longa) were obtained from Akwatta, a local market in Enugu, Nigeria. It was authenticated by a consultant taxonomist at the Department of Plant Science and Biotechnology, University of Nigeria, Nsukka, and a voucher specimen was deposited at the herbarium with reference number [UNH 205'] for future reference.

\section{Preparation of Aqueous Extract of Tumeric.}

Preparation as described by $\mathrm{Al}$-Taee et al. ${ }^{2}$ was done, with slight modification. Briefly, water extraction of turmeric was prepared by boiling $100 \mathrm{gm}$ in $1000 \mathrm{ml}$ distilled water over low flame for 15 minutes, using a heat-stable flask. The content of the flask was allowed to cool for 20 minutes. After cooling, the content of the flask was sieved using clean muslin cloth and filtered with Whatman No.1 filter paper 
(Whatman Clifton, NJ, USA). The filtrate was used to prepare the required concentration.

\section{Phytochemical Analysis of Tumeric:}

Preliminary phytochemical screening of tumeric (curcuma longa) was carried out at Department of Pharmacognosy, Faculty of Pharmaceutical Science, University of Nigeria Nsukka. Procedures outlined by Trease and Evans ${ }^{3}$ were employed for the analyses.

\section{Reagents and Solutions}

\section{Preparation of high-cholesterol diet (HCD)}

A mixture of $75 \mathrm{~g}$ of commercially available cholesterol powder and $9 \mathrm{~g}$ of sodium deoxycholate (bile salt added to increase bioavailability) was dissolved in coconut oil and made up with the same solvent to $300 \mathrm{ml}$ to give a stock concentration of $250 \mathrm{mg} / \mathrm{ml}$.

\section{Carbimazole and atorvastatin solutions}

Stock concentrations $(2 \mathrm{mg} / \mathrm{ml})$ of carbimazole (Hovid@ ${ }^{\circledR}$ Inc., Malaysia) and atorvastatin (pfizer® Inc., New York, USA) were prepared and used for the research.

\section{Induction of dyslipidaemia and cardiac injury}

Each rat was co-administered with $\mathrm{HCD}$ at the dose of $2000 \mathrm{mg} / \mathrm{kg}$ and high dose of $60 \mathrm{mg} / \mathrm{kg}$ carbimazole solution daily for eight weeks.

\section{Animals}

Twenty (20) apparently healthy adult male albino rats about three (3) months old were used for the research. They were obtained from the animal house of the college of medicine, University of Nigeria Teaching Hospital (UNTH) Enugu. They were housed under standard condition of temperature $\left(28 \pm 3^{\circ} \mathrm{C}\right)$ and a 12 hours light/ 12 hours dark cycle at the animal house at Anatomy department, College of medicine, University of Nigeria, Enugu Campus. They were allowed to acclimatize for a period of two (2 weeks) and the experimental protocol was approved by the institution animal ethic committee of the University of Nigeria, Nsukka, Enugu State, Nigeria (UNTH/CSA. 1205/VOL. 19).

\section{Design}

Group A (negative control) received $60 \mathrm{mg} / \mathrm{kg}$ of carbimazole, $2000 \mathrm{mg} / \mathrm{kg}$ of HCD only for 8 weeks.

Group B (positive control) received carbimazole, HCD and $20 \mathrm{mg} / \mathrm{kg}$ of Atorvastatin for 8 weeks.

Group C (test) received carbimazole, HCD and $400 \mathrm{mg} / \mathrm{kg}$ of AECL.

Group D (normal control) was given neither HCD nor the extract; therefore no treatment.

\section{Sacrificing of Animal and Sample Collection}

After eight weeks, the animals were sacrificed under chloroform anaesthesia. About $6 \mathrm{ml}$ of blood was collected into plain tubes, centrifuged to obtain serum for estimation of lipid profile (Total Cholesterol, HDL-cholesterol and triglyceride. The hearts were harvested for histopathological studies.

\section{Biochemical analysis}

Total cholesterol was estimated using cholesterol oxidase method as described by Mizoguchi et al.4, HDL-C was determined using precipitation method as described by Hafiane and Genest ${ }^{5}$ and Triglyceride (TG) was estimated using glycerol phosphate oxidase method as described by AlAnzi and Zinn. ${ }^{6}$

\section{Histopathological analysis}

The excised heart was processed using the paraffin wax embedding technique, sectioned at 5 microns and stained using the Haematoxylin and Eosin $[\mathrm{H}$ and E] staining procedure (Baker et al.7. The histological sections were examined using an Olympus TM light microscope

\section{Histopathological image analysis}

Interpretation was done following standard guidelines as described by Gurcan et al. ${ }^{8}$

\section{Statistical analysis}

Data analysis was done using GraphPad prism version 7.0 (GraphPad, San Diego, CA, USA). The results of the biochemical assays were reported as mean \pm SEM (standard error of mean). One way analysis of variance (ANOVA), followed by the Tukey post hoc analysis, was used to test for the level of significance $(\mathrm{p}<0.05)$.

\section{RESULTS}

\section{Phytochemical results}

Phytochemical analysis indicated the presence of alkaloids, flavonoids, tannins, saponins, terpenoids, glycosides, tannins, phenolic compounds, terpenoids and phytosterols in the plant extract (Table 1).

Table 1: qualitative phytochemical results of aqueous extract of Curcuma longa

\begin{tabular}{|c|c|}
\hline Constituent & Indication \\
\hline Carbohydrate & - \\
\hline Reducing Sugar & - \\
\hline Alkaloids & + \\
\hline Glycosides & + \\
\hline Saponins & + \\
\hline Tannins & + \\
\hline Flavonoids & ++ \\
\hline Resins & - \\
\hline Proteins & - \\
\hline Oils & - \\
\hline Phenolic Compounds & ++ \\
\hline Terpenoids & ++ \\
\hline Phytosterols & + \\
\hline
\end{tabular}

Key: ++ = present; + = present (in trace amount); - = absent

\section{Biochemical results}

Table 2 shows the results of serum lipid profile parameters: total cholesterol (TC), HDL and Triglyceride (TG) levels in the different experimental. From the results, AECL showed significant antihyperlipidaemic potentials $\left({ }^{*} \mathrm{P}<0.05\right)$ in comparison with negative control (HCD+CBM). Furthermore, it was observed that the standard drug (atorvastatin) showed much better antihyperlipidaemic effects in the rats than the extract. 
Table 2: Comparison of serum lipid profile of treated groups with negative controls.

\begin{tabular}{|c|c|c|c|}
\hline Groups & $\begin{array}{c}\text { Serum TC } \\
\text { (mmol/L) }\end{array}$ & $\begin{array}{c}\text { Serum HDL-C } \\
\text { (mmol/L) }\end{array}$ & $\begin{array}{c}\text { Serum TG } \\
\text { (mmol/L) }\end{array}$ \\
\hline $\begin{array}{c}\text { HCD+CBM } \\
\text { (Negative Control) }\end{array}$ & $6.02 \pm 0.34$ & $1.30 \pm 0.09$ & $2.52 \pm 0.29$ \\
\hline $\begin{array}{c}\text { HCD+CBM+ATOR } \\
\text { (Positive Control) }\end{array}$ & $5.06 \pm 0.08^{* *}$ & $2.35 \pm 0.11^{*}$ & $1.38 \pm 0.05^{*}$ \\
\hline $\begin{array}{c}\text { HCD+CBM+AECL } \\
\text { (Test) }\end{array}$ & $5.43 \pm 0.29^{*}$ & $2.26 \pm 0.12^{*}$ & $1.65 \pm 0.03$ \\
\hline $\begin{array}{c}\text { Normal } \\
\text { Control }\end{array}$ & $4.98 \pm 0.13^{*}$ & $2.40 \pm 0.09^{*}$ & $1.39 \pm 0.04^{*}$ \\
\hline
\end{tabular}

Values given as Mean \pm SEM. ${ }^{* *} \mathrm{P}<0.01$ or $* \mathrm{P}<0.05$ is significant when $(\mathrm{HCD}+\mathrm{CBM})$ is compared with all other groups.

\section{Histopathological results}

In figure 1, photomicrograph of heart from normal control rats revealed no histopathological alteration (Figure 1D). There was presence of significantly extensive fibrosis and mild infiltration by inflammatory cells in rat treated with oral administration of HCD and high dose carbimazole (Figure 1A); however non-significant alterations were observed in rats treated with atorvastatin $(20 \mathrm{mg} / \mathrm{kg})$ and AECL $(400 \mathrm{mg} / \mathrm{kg})$ separately (Figures $1 \mathrm{~B}$ and $1 \mathrm{C}$ ) respectively.
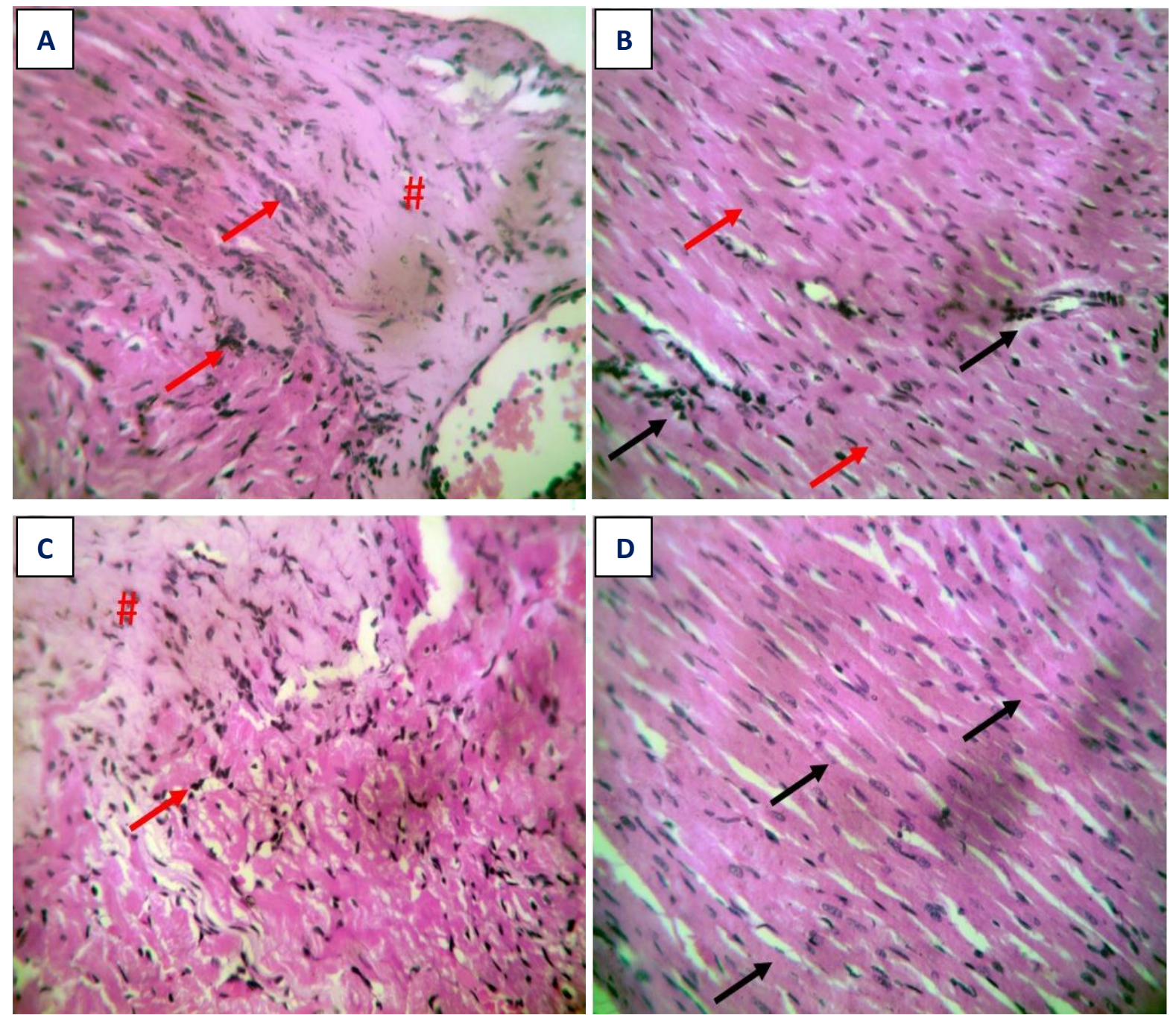

Figure 1: Histopathology and photomicrograph of heart. (A) Co-administration of high cholesterol diet (HCD) and carbimazole (CBM)-treated rats. Myocardial fibres are distorted. Evidence of extensive fibrosis (\#) and mild infiltration by inflammatory cells (arrows). (B) HCD + CBM + Atorvastatin- treated rats. Cardiac fibres (red arrow) appear normal with very mild infiltration by inflammatory cells (black arrows) (C) HCD + CBM + AECL-treated rats: Evidence of fibrosis (\#) and mild infiltration by inflammatory cells (arrows). (D) Normal control rats. No pathological lesions in the myocardial fibres.(black arrow). [Stain: $\mathrm{H}$ and $\mathrm{E} ; \times 400]$. 


\section{DISCUSSION}

Thyroid hormone deficiency has been implicated as the cause of hypercholesterolaemia in hypothyroid patients Chandurkar et al. ${ }^{9}$ Thus carbimazole was used in the study to induce hypothyroidaemia which enabled rapid onset of hyperchoresterolaemia in the experimental rats.

Aside enhancing the buildup of cholesterol in the blood, the mechanism of cardiac injury by carbimazole is not well understood, although the mechanism of testicular injury by carbimazole has been extensively reported to be due to increase in oxidative stress (Orji et al.10; Saber et al.11 Possibly the coadministration of high cholesterol diet and the high dose carbimazole to the rats for 8 weeks synergistically induced the chronic cardiac muscle effects observed in this study. Therefore, the cardiac muscle changes could be explained on the basis of increased oxidative stress.

In the last few decades, there has been the growing use of herbal medicines because most plants are believed to have medicinal value, turmeric being one of them. The aim of this study was to evaluate the antidyslipidaemic effect of aqueous extract of Curcuma longa (AECL) in hypercholesterolaemic rats; using atorvastatin as a reference drug. The AECL in this study prevented dyslipidaemia, and cardiomyopathy after the 8 weeks treatment period. Treatment with atorvastatin induced significant antidyslipidaemic effect and cardiac protection. The histopathological results showed concomitant association with our biochemical results.

The effects observed in this study could be due to the singular or combined action of the bioactive phytochemicals present in turmeric extracts. Hyperlipidaemia and oxidative stress following the hypercholesterolaemic diet could be prevented by endogenous and exogenous antioxidants. ${ }^{12}$ The consumption of plant products was shown to reduce hypercholesterolaemia, oxidative stress, homocystienaemia, endothelia dysfunction and blood pressure.13,14 These beneficial effects have been partly attributed to the compound which possesses antioxidation. Tumeric is rich in both anti-inflammatory and antioxidant phytochemicals such flavonoids.

WHO reports that, more than $60 \%$ of the societies in lowincome countries rely upon medicinal plants for their primary health care because of their easy accessibility, low cost and minimal adverse effects. ${ }^{15}$ Over the years, scientists have been researching on food and plant products that possess protective effects against cardiac injury. It was discovered that diets rich in natural antioxidants (especially flavonoids) have potent effects against oxidative stress caused by cardiotoxic substances. ${ }^{16}$ The result of the preliminary phytochemical analysis of Curcuma longa (tumeric) revealed moderate presence of flavonoids and phenols $(++)$, and alkaloids and tannins $(+)$. The findings we observed could be as a result of the flavonoid and/or phenolic compounds present in the tumeric.

Observation from biochemical and histological results show that consumption of Curcuma longa (tumeric) may serve as a healthy diet and as well be an effective intervention in improving cardiomyopathy. This study and other previous reports suggest a protective role of dietary Curcuma longa (tumeric) against biochemical and histopathological alterations by toxic agents.
Limitation: Cardiac markers such as: troponin, myoglobin, CRP etc should have been measured to truly ascertain tumeric's true cardio protection.

\section{CONCLUSION}

This study showed that the aqueous extract of Curcuma longa (AECL) has effect on lipid metabolism and prevents cardiomyopathy in albino rats fed a high cholesterol diet and high dose Carbimazole. Therefore, the alterations in the serum lipid by the aqueous extract of Curcuma longa (AECL) may not predispose the heart to atherosclerosis or its associated cardiomyopathy or infarction.

\section{Competing Interests Statement: The authors declare} no conflicts of interest.

\section{REFERENCES}

1. Uchendu IK, Onwukwe SO, Agu CE, Orji CO, Eluke BC, Nwosu TF. Hypolipidaemic and renoprotective effects of Glycine max (soy bean) against lipid profile and renal biochemical alterations in hypercholesterolemic rat. International Journal of Biomedical Research. 2016; 7:822-828.

2. Al-Taee MF, Al-Ahmed HI, Abdul Malek HW. Studying the Effect of Aqueous Extract from Curcuma Longa on Some Parameters of Cytogenetic, Immunity and Fertility in Female Mice. Baghdad Science Journal. 2011; 8:73-879.

3. Trease G, Evans SM. Pharmacognosy: (15 th Edition). English Language Book Society. Bailliere Tindall, London, 2002; pp 23 67.

4. Mizoguchi T, Edano T, Koshi T. A method of direct measurement for the enzymatic determination of cholesteryl esters. J Lipid Res. 2004; 45:396-401

5. Hafiane A, Genest J. High density lipoproteins: Measurement techniques and potential biomarkers of cardiovascular risk. Biochimical et Biophysica Acta- Clinical. 2015; 3:175-188.

6. Al-Anzi B, Zinn K. Colorimetric Measurement of Triglycerides Cannot Provide an Accurate Measure of Stored Fat Content in Drosophila. PLoS One, 2010; 5(8):e12353.

7. Baker FJ, Silverton RE, Pallister CJ Baker and Silverton's Introduction to Laboratory Technology. 7th Edition, Butterworth-Heinemann, Wobrun, MA, USA, 1998; page 448.

8. Gurcan MN, Boucheron L, Can A, Madabhushi A, Rajpoot N, Yener B. Histopathological image analysis: A review. IEEE Reviews in Biomedical Engineering. 2009; 2:147-171.

9. Chandurkar V, Shik, J, Randell E. Hyperthyroidism caused by proteinuria and induction of urinary thyroixine loss: case report and subsequent investigation. Journal of Endocrine Practice, 2008; 14:97-103.

10. Orji OC, Uchendu IK, Agu CE, Nnedu EB, Okerreke AN, Orji GC. Combined Effects of Vitamin $\mathrm{C}$ and Tomato Extract (Lycopersicon Esculentum) on Carbimazole-induced Alterations in the Testes of Male Albino Rats. Indian Journal of Physiology and Pharmacology. 2018; 62:380-384.

11. Saber AS, Sobhy EE, Yosry, AO. Ahmed. Impact of ginger aqueous extract on carbimazole induced testiculardegenerative alterations and oxidative stress in albino rats. Journal of Costal Life Medicine. 2017; 5:167-173.

12. Silaste ML, Ranatala M, Alfthan G, Aro A. Kesaniemi YA. Plasma homocysteine concentration is decreased by dietary intervention. British Journal of Nutrition. 2003; 89:295-301.

13. Panche AN, Diwan AD, Chandra SR. Flavonoids: an overview. Journal of Nutritional Science. 2016; 5:1-15.

14. Cherrak SA, Mokhtari-Soulimane N, Berroukeche F, Bensenane $\mathrm{B}$, Cherbonnel $\mathrm{A}$, Merzouk $\mathrm{H}$, Elhabiri $\mathrm{M}$. In vitro antioxidant versus metal ion chelating properties of flavonoids: A structureactivity investigation. Plos One, 2016; 11(10): e0165575.

15. Mahmoud AM, Bautista RJH, Sandhu MA, Hussein OE. Beneficial effects of citrus flavonoids on cardiovascular and metabolic health. Oxidative Medicine and Cellular Longevity. 2019; 2019:ID 5484138, 19 pages.

16. Kooti W, Hasanzadeh-Nooti Z, Sharafi-Ahvazi N, Asadi-Samani M, Ashtary-Larky D. Phytochemistry, Pharmacology and therapeutic uses of black seed (Nigella Savita). Chinese Journal of Natural Medicines. 2016; 14(10):732-745. 